\title{
Grey-box Modeling for System Identification of Household Refrigerators: a Step Toward Smart Appliances
}

Costanzo, Giuseppe Tommaso; Sossan, Fabrizio; Marinelli, Mattia; Bacher, Peder; Madsen, Henrik

Published in:

Proceedings of IEEE 4th International Youth Conference on Energy

Link to article, DOI:

10.1109/IYCE.2013.6604197

Publication date:

2013

Document Version

Early version, also known as pre-print

Link back to DTU Orbit

Citation (APA):

Costanzo, G. T., Sossan, F., Marinelli, M., Bacher, P., \& Madsen, H. (2013). Grey-box Modeling for System Identification of Household Refrigerators: a Step Toward Smart Appliances. In Proceedings of IEEE 4th International Youth Conference on Energy IEEE. https://doi.org/10.1109/IYCE.2013.6604197

\section{General rights}

Copyright and moral rights for the publications made accessible in the public portal are retained by the authors and/or other copyright owners and it is a condition of accessing publications that users recognise and abide by the legal requirements associated with these rights.

- Users may download and print one copy of any publication from the public portal for the purpose of private study or research.

- You may not further distribute the material or use it for any profit-making activity or commercial gain

- You may freely distribute the URL identifying the publication in the public portal 


\section{Grey-box Modeling for System Identification of Household Refrigerators: a Step Toward Smart Appliances}

\author{
Giuseppe Tommaso Costanzo, \\ Fabrizio Sossan and Mattia Marinelli \\ Center for Electric Power and Energy \\ Technical University of Denmark, Risø Campus \\ 4000 Roskilde (DK) \\ \{guco, faso, matm\}@elektro.dtu.dk
}

\author{
Peder Bacher and Henrik Madsen \\ DTU Compute \\ Technical University of Denmark \\ 2800 Lyngby (DK) \\ $\{\mathrm{pb}, \mathrm{hm}\} @$ imm.dtu.dk
}

\begin{abstract}
This paper presents the grey-box modeling of a vapor-compression refrigeration system for residential applications based on maximum likelihood estimation of parameters in stochastic differential equations. Models obtained are useful in the view of controlling refrigerators as flexible consumption units, which operation can be shifted within temperature and operational constraints. Even if the refrigerators are not intended to be used as smart loads, validated models are useful in predicting units consumption. This information can increase the optimality of the management of other flexible units, such as heat pumps for space heating, in order to smooth the load factor during peak hours, enhance reliability and efficiency in power networks and reduce operational costs.
\end{abstract}

Keywords-Refrigerators, Stochastic processes, System identification, Load shifting.

\section{INTRODUCTION}

The World Business Council for Sustainable Development estimates that in most countries buildings account approximately for the $30-40 \%$ of total energy consumption [1]. Energy consumption in a building can be related to such applications as space heating and building automation (including security systems and ICT infrastructures) or to human activities. It emerges that controlling loads with building automation systems can enhance the overall demand flexibility and enable a win-win situation, where customers adjust their consumption upon economic inducements and utilities avoid grid overloads by spreading the demand during off-peak periods [2]. In this context, validated models of appliances are necessary in the design of systems for residential demand side management and in testing and benchmarking controllers for energy consumption in Smart Buildings.

Devices or processes associated to thermal storage present intrinsic flexibility in consumption as long as their operation is managed within certain comfort bounds. One example is space heating, which can be used for peak shaving [3], but also other types of thermal storages (such as refrigerators or water chillers) offer flexibility in consumption.

This paper presents the grey-box modeling of a vaporcompression refrigeration system for residential applications using stochastic differential equations (SDEs). The grey-box approach offers the possibility of providing a combined physical and statistical description of the system. The identified models are useful in the view of controlling refrigerators as flexible consumption units, which operation can be shifted within temperature and operational constraints. Even if the refrigerators are not intended to be used as smart loads, validated models are useful in predicting units consumption. This information can increase the optimality of the management of other flexible units, such as heat pumps for space heating, in order to smooth the load factor during peak hours, enhance reliability and efficiency in power networks and reduce operational costs. Household refrigerator modeling and performance assessment has been previously addressed with such approaches as dynamic simulation [4], steady state simulation [5], or CFD models [6].

The motivation to this study is to provide simple, readyto-use and validated lumped parameter (stochastic state space) models for household refrigerators. The approach used is formed by forward model selection and validation based on experimental data and statistical testing. The software used is CTSM [7], which is based on maximum likelihood estimation. Parameters as thermal masses, evaporator thermal resistance, U-value of insulation and refrigeration cycle Coefficient of Performance (COP) are identified for each model in terms of expected value and variance. Convergence of estimation is also troubleshot.

\section{EXPERIMENTAL SETUP}

The experimental setup consists of: household refrigerator of capacity 60 liters with freezer bay and single compressor, power meter DEIF-MIC2, ADAM-6024 ADC card, four calibrated temperature sensors TI-LM35, one remotely controlled power outlet. Every second the refrigerator internal temperatures, ambient temperatures and refrigerator active power consumption are synchronously measured. Given the stratification of temperatures in the refrigeration chamber, two sensors are used in order to provide the average internal temperature. The same approach is used for determining the ambient temperature.

The refrigerator thermostat is set to supply the minimum temperature such that it is possible, within a temperature range, to enable or disable the compressor operation directly via the controlled power outlet.

\section{MODEL OF REFRIGERATION CYCLE}

This section presents a simple model for vaporcompression refrigeration system based on steady state one- 
dimensional heat transfer equations. It is deemed valid to develop a static model of the vapor-compression cycle since it has faster dynamics if compared to the cold storage. Figure 1 shows a schematic representation of common refrigeration system for household applications.

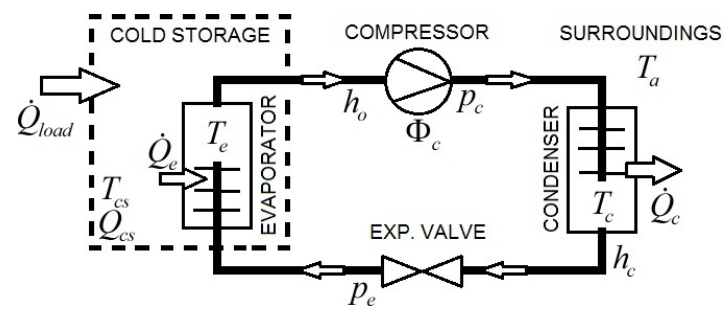

Fig. 1. Single stage vapor-compression refrigeration system.

A simple model of the system is:

$$
\frac{d Q_{c s}(t)}{d t}=\dot{Q}_{l o a d}(t)-\dot{Q}_{e}(t)
$$

where:

$$
\begin{aligned}
& d Q_{c s}=m_{c s} c_{c s} d T_{c s} \\
& \dot{Q}_{\text {load }}=U A_{c s}\left(T_{a}-T_{c s}\right) \\
& \dot{Q}_{e}=\dot{m}_{r}\left[h_{o}\left(p_{e}\right)-h_{c}\left(p_{c}\right)\right] \approx C O P \cdot \Phi_{c} \\
& \dot{m}_{r}=N_{c} \alpha \rho_{r}\left(p_{e}\right)
\end{aligned}
$$

In Eq.2, $m_{c s}$ is the cold storage mass and $c_{c s}$ is its specific heat capacity. $h_{o}$ and $h_{c}$ are the evaporation and condensation enthalpies at the evaporation and condensation pressures, respectively $p_{e}$ and $p_{c}$. $U A_{c s}$ is the overall transmittance coefficient from the refrigeration chamber to the ambient and $\dot{m}_{r}$ is the refrigerant mass flow rate. COP is the overall coefficient of performance, here defined as the ratio between $\dot{Q}_{e}$, the thermal power extracted at evaporator side, and $\Phi_{c}$, the refrigerator electrical consumption.

\section{GREY BOX MODELING}

Grey-box modeling is a framework for identifying a system description that combines prior physical knowledge of the system with information obtained from experimental data. For parameters estimation and system control it is convenient to use stochastic state space models [8], where the dynamical part of the model, the state, is described by Stochastic Differential Equations (SDEs) and the output is given by a discrete time algebraic equation describing how the observations are linked to the state. The parameters estimation and uncertainty assessment is obtained with statistical methods [9]. A stochastic differential equation (SDE) is a differential equation where one or more terms are stochastic processes, so that the solution is a stochastic process itself.

This section presents three different models of increasing complexity, all of which are developed under the hypotheses of: homogeneous materials, linear cooling cycle with constant COP and neglect of freezer compartment.

It is convenient to use electric thermal equivalent models in order to easily depict the models' structure and relate the identified parameters to physical quantities such as thermal transmittances and efficiency coefficients.

\section{A. Model $T_{i}$}

Here the refrigeration chamber is represented with a thermal mass, $C_{i}$, while the envelope (insulation) is modeled with a pure thermal resistance, $R_{i a}$ (Fig. 2):

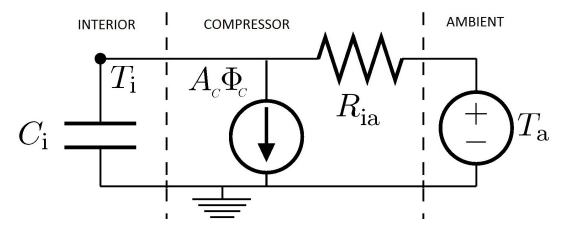

Fig. 2. Refrigerator preliminary model (electrical equivalent): $T_{i}$.

The compressor has a direct refrigeration effect, so that it is modeled as a current generator. This model is a single state stochastic state space model:

$$
\begin{aligned}
& d T_{i}=\left[\frac{1}{C_{i} R_{i a}}\left(T_{a}-T_{i}\right)-\frac{1}{C_{i}} A_{c} \Phi_{c}\right] d t+\sigma_{1} d w \\
& y_{t_{k}}=T_{i, t_{k}}+e_{t_{k}}, \quad e_{t_{k}} \sim N\left(0, \sigma_{e}^{2}\right)
\end{aligned},
$$

where $A_{c}$ is the cycle COP and $w$ is a standard Wiener process independent from the residual $e_{t_{k}} . T_{a}$ is the ambient temperature, $T_{i}$ is the refrigeration chamber temperature and $\Phi_{c}$ is the compressor active power consumption. Parameters' units are:

$$
\begin{gathered}
T_{i}=\left[{ }^{o} C\right], R_{i}=\left[\frac{{ }^{o} C}{W}\right], C=\left[\frac{J}{K}\right], \\
A_{c}=[\text { scalar }], \Phi_{c}=\left[\frac{k J}{s}\right] .
\end{gathered}
$$

\section{B. Model $T_{i} T_{\text {evap }}$}

This model extends the previous one by accounting for the heat transfer between the refrigeration chamber and the evaporator. This leads to an additional state for the evaporator temperature, $T_{e}$ :

$$
\begin{aligned}
& d T_{i}=\left[\frac{1}{C_{i} R_{i a}}\left(T_{a}-T_{i}\right)+\frac{1}{C_{i} R_{e i}}\left(T_{e}-T_{i}\right)\right] d t+\sigma_{1} d w_{1} \\
& d T_{e}=\left[\frac{1}{C_{\text {evap }} R_{e i}}\left(T_{i}-T_{e}\right)-\frac{1}{C_{\text {evap }}} A_{c} \Phi_{c}\right] d t+\sigma_{2} d w_{2} \\
& y_{t_{k}}=T_{i, t_{k}}+e_{t_{k}}, \quad e_{t_{k}} \sim N\left(0, \sigma_{e}^{2}\right)
\end{aligned}
$$

where $w_{1}, w_{2}$ and $e_{t_{k}}$ are independent.

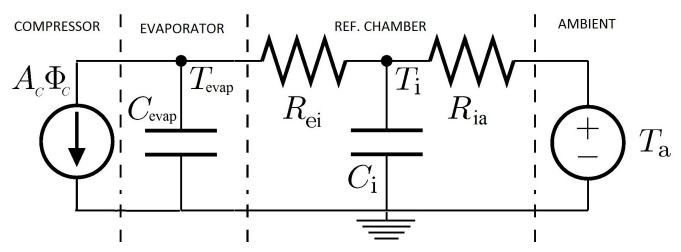

Fig. 3. Refrigerator model (electrical equivalent): $T_{i} T_{\text {evap }}$.

\section{Model $T_{i} T_{\text {evap }} T_{e}$}

Here the $T_{i} T_{e}$ model is extended by adding a state to the envelope and separating the envelope thermal resistance in inner resistance, $R_{i e}$, and outer resistance, $R_{e a}$ :

$$
\begin{aligned}
& d T_{\text {evap }}=\left[\frac{1}{C_{\text {evap }} R_{\text {evi }}}\left(T_{i}-T_{\text {evap }}\right)-\frac{1}{C_{\text {evap }}} A_{c} \Phi_{c}\right] d t+\sigma_{1} d w_{1} \\
& d T_{i}=\left[\frac{1}{C_{i} R_{\text {evi }}}\left(T_{\text {evap }}-T_{i}\right)+\frac{1}{C_{i} R_{i e}}\left(T_{e}-T_{i}\right)\right] d t+\sigma_{2} d w_{2} \\
& d T_{e}=\left[\frac{1}{C_{e} R_{i e}}\left(T_{i}-T_{e}\right)+\frac{1}{C_{e} R_{e a}}\left(T_{a}-T_{e}\right)\right] d t+\sigma_{3} d w_{3} \\
& y_{t_{k}}=T_{i, t_{k}}+e_{t_{k}}, \quad e_{t_{k}} \sim N\left(0, \sigma_{e}^{2}\right)
\end{aligned}
$$


where $w_{1}, w_{2}, w_{3}$ and $e_{t_{k}}$ are independent. Follows the electric equivalent model:

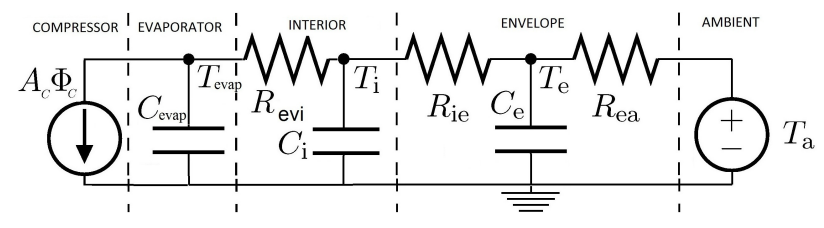

Fig. 4. Refrigerator model (electrical equivalent): $T_{i} T_{\text {evap }} T_{e}$.

\section{A-PRIORI PARAMETERS}

Grey-box modeling can benefit from calculated or judged value of parameters to be used as initial value for the estimation process. This section presents an initial estimation of physical parameters for the refrigeration chamber, including the glass shelves and the plastic drawer. The refrigerator insulation is assumed to be made by extruded expanded polystyrene (XPS).

\section{A. Refrigeration chamber (thermal mass)}

a) $\operatorname{Air}\left(0^{\circ} \mathrm{C}\right.$, sea level, dry air $)$ :

$$
\begin{aligned}
& c_{v-a i r}=1297 \frac{J}{m^{3} K}, \quad V_{a i r}=0.111456 \mathrm{~m}^{3} \\
& C_{\text {air }}=c_{v-\text { air }} V_{\text {air }} \simeq 145 \frac{\mathrm{J}}{K} .
\end{aligned}
$$

b) Glass (tempered glass):

$$
\begin{aligned}
& V_{\text {shelf }(1,2)}=8.25 \cdot 10^{-4} \mathrm{~m}^{3}, V_{\text {shelf }(3)}=4.41 \cdot 10^{-4} \mathrm{~m}^{3} \\
& \rho_{\text {glass }}=2500 \frac{\mathrm{kg}}{\mathrm{m}^{3}}, c_{m-\text { glass }}=0.84 \frac{\mathrm{J}}{\mathrm{gK}} \\
& m_{\text {glass }}=\rho_{\text {glass }}\left(2 \cdot V_{\text {shelf }(1,2)}+V_{\text {shelf }(3)}\right)=5.232 \mathrm{~kg} \\
& C_{\text {glass }}=c_{m-\text { glass }} m_{\text {glass }} \simeq 4395 \frac{\mathrm{J}}{\mathrm{K}} .
\end{aligned}
$$

c) Plastic (a rough estimation for the drawer):

$$
\begin{aligned}
& \rho_{\text {polyetylene }}=910 \frac{\mathrm{kg}}{\mathrm{m}^{3}}, V_{\text {drawer }} \simeq 7.096 \cdot 10^{-4} \mathrm{~m}^{3} \\
& m_{\text {drawer }}=\rho_{\text {polyetylene }} V_{\text {drawer }} \simeq 0.65 \mathrm{~kg} \\
& c_{m-\text { polyetylene }}=1.67 \frac{\mathrm{J}}{\mathrm{gK}} \\
& C_{\text {plastic }}=m_{\text {drawer }} c_{\text {polyetylene }} \simeq 1086 \frac{\mathrm{J}}{\mathrm{K}} .
\end{aligned}
$$

d) Total thermal mass of refrigeration chamber:

$$
C_{i}=C_{a i r}+C_{\text {glass }}+C_{\text {plastic }}=5626 \frac{\mathrm{J}}{\mathrm{K}}
$$

\section{B. Envelope: thermal mass and resistance}

It is reasonable to assume that the insulation layer has size: $44 \mathrm{~cm}$ depth (D), $55 \mathrm{~cm}$ height $(\mathrm{H}), 48 \mathrm{~cm}$ width (L), and $3.5 \mathrm{~cm}$ thickness (d):

$$
\begin{aligned}
& \rho_{\text {poly }}=50 \frac{\mathrm{kg}}{\mathrm{m}^{3}}, c_{m-\text { poly }}=1.3 \frac{\mathrm{J}}{\mathrm{gK}}, \lambda_{\text {poly }}=0.033 \frac{\mathrm{W}}{\mathrm{mK}} \\
& S_{\text {envelope }}=1.4344 \mathrm{~m}^{2}, V_{\text {envelope }}=d \cdot S_{\text {envelope }} \simeq 0.043 \mathrm{~m}^{3} \\
& m_{\text {envelope }}=\rho_{\text {poly }} V_{\text {envelope }}=2.15 \mathrm{~kg}
\end{aligned}
$$

e) Total thermal mass and resistance of the envelope:

$$
\begin{aligned}
& C_{e}=m_{\text {envelope }} c_{m-\text { poly }}=2797 \frac{\mathrm{J}}{\mathrm{K}} \\
& R_{e}=\left(\frac{1}{\lambda_{\text {poly }}} \cdot \frac{d}{S}\right) \simeq 0.74 \frac{K}{W}
\end{aligned}
$$

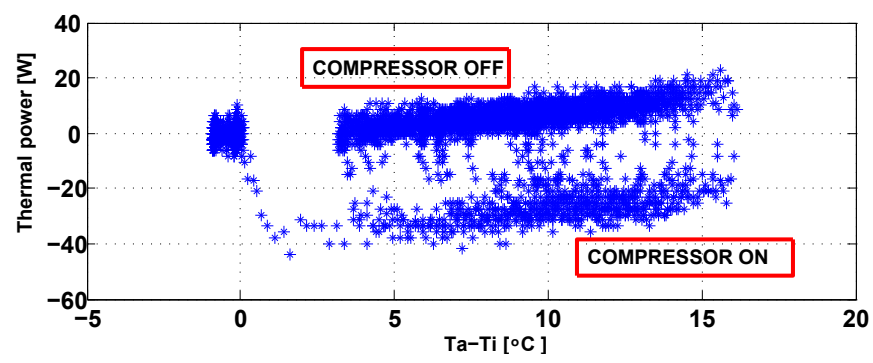

Fig. 5. Refrigerator operation: thermal power at refrigeration chamber v.s. temperature drop.

\section{Refrigeration cycle (COP)}

Figure 5 shows the total thermal power acting on the refrigeration chamber versus the temperature drop. When the compressor is not operating, the thermal power coming from the ambient accounts for approximately $8 \mathrm{~W}$, whereas during the refrigeration cycle the total thermal power at the refrigeration chamber is approximately $-30 \mathrm{~W}$. Therefore the compressor generates approximately -38 thermal watts with an average electrical consumption of 50 watts, so that an initial value of the $\mathrm{COP}$ is:

$$
C O P \simeq 0.76
$$

The COP could seem low, but notice that here it is approximated by the ratio between thermal power extracted from the refrigeration chamber and the electrical power consumed by the compressor and hence it includes also the mechanical and electrical efficiency.

\section{System IDENTIFICATION}

Parameter estimation is carried out using CTSM, which provides a tool for semi-physical modeling and identification of dynamic systems based on stochastic differential equations [10]. CTSM provides methods for estimating unknown parameters of the model from data, including parameters in the diffusion term, using either the maximum likelihood (ML) method [11] or the maximum a posteriori (MAP) method. Both methods allow for several independent data sets to be used and are both sound statistically based estimation methods, which means that once the parameters have been estimated, statistical methods can be applied to investigate the quality of the model [12].

Figure 6 shows the process of model identification and validation. A first set of data, called identification data (see Fig. 7), is used for estimating model parameters and initial values of the states. Then the model, using the power input and room temperature from the same identification data, is used to calculate the one-step ahead predictions of the output. These predictions are subtracted from the measured output to form the residuals, which are analyzed for their white noise properties. If the model prediction residual is statistically close to white noise, the model is good [9]; therefore the auto correlation function is used to analyze the residuals (see, eg., Fig. 9). This procedure is called model validation.

A model can also be validated with another data set (see, eg., Fig. 14). If the results are good, this procedure gives a good indication of model robustness and correct identification. 


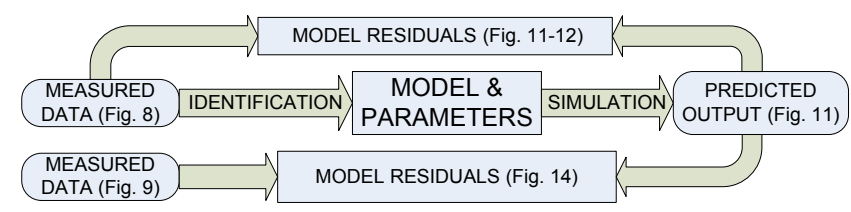

Fig. 6. Process of parameters identification and model validation.

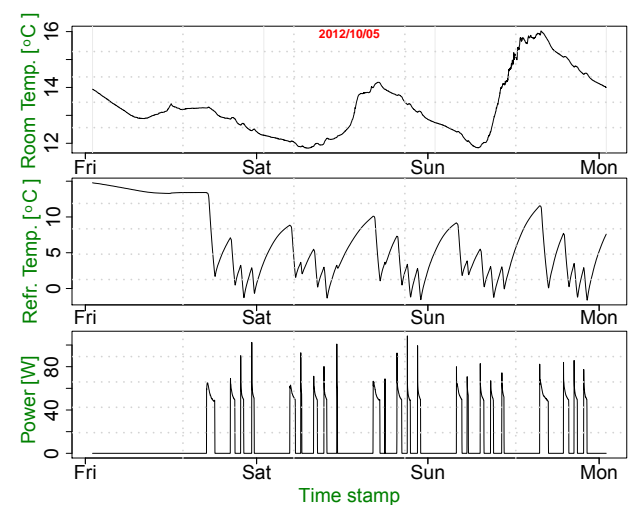

Fig. 7. Refrigerator operation: ambient temperature, internal temperature and electrical power consumption - identification data set.

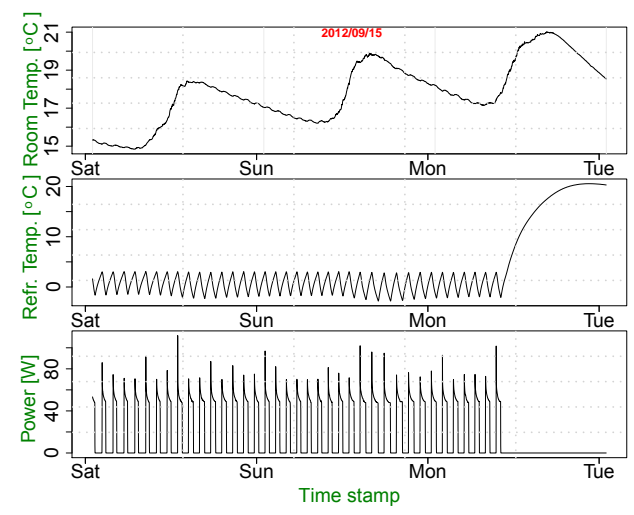

Fig. 8. Refrigerator operation: ambient temperature, internal temperature and electrical power consumption - validation data set.

\section{A. Parameters of the $T_{i}$ model}

TABLE I. IDENTIFIED PARAMETERS: $T_{i}$ MODEL

\begin{tabular}{|c||l||l|}
\hline PARAMETER & VALUE & STD. DEV. \\
\hline$R_{i a}$ & 1.4749 & 2.5617 \\
\hline$C_{i}$ & $8.9374 \cdot 10^{3}$ & $1.5481 \cdot 10^{4}$ \\
\hline$T_{i}(0)$ & 14.774 & $2.9795 \cdot 10^{-2}$ \\
\hline$A_{c}$ & 0.58092 & 1.0075 \\
\hline $\exp \left(\sigma_{1}\right)$ & -5.4552 & $1.2511 \cdot 10^{-2}$ \\
\hline $\exp (e)$ & -24.332 & 75.437 \\
\hline Loglikelihood & 7995.168 & \\
\hline
\end{tabular}

Figure 9 shows the residuals analysis of the model described by (3) with respect the identification data set. The first graph on the left presents the auto correlation function (ACF) of residuals, the graph in the middle the periodogram and the graph on the right the cumulated periodogram. High correlation of residuals at low values of lags indicates that the dynamics are not well modeled, and hence it is concluded that the model is too simple to describe the dynamics.

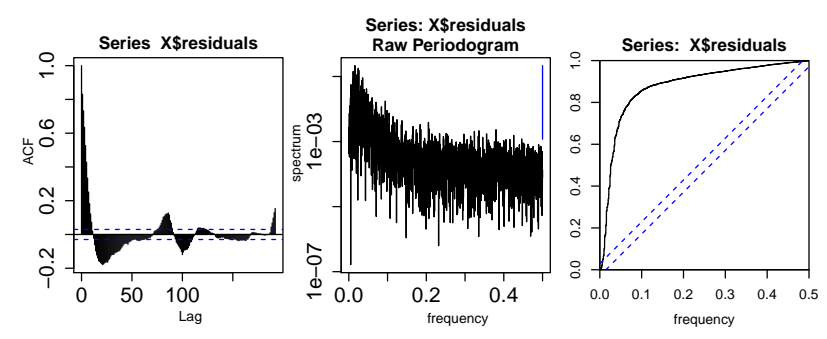

Fig. 9. Model residuals analysis: $T_{i}$.

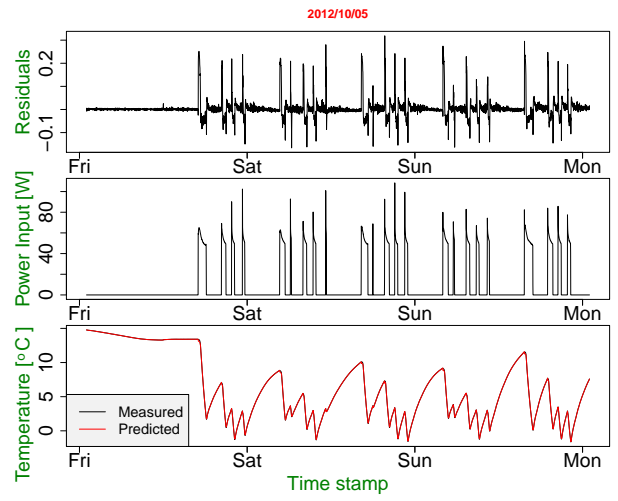

Fig. 10. Residuals, input and output of Model: $T_{i}$.

Figure 10 presents the residuals (top chart), the power input (mid chart) and the predicted and measured temperature in the refrigerator. From these plots it is possible to depict that model residuals are higher at the beginning of refrigeration cycle. Such situation was expected, since the non-linearities and complexity of the refrigeration cycle are not considered in the model. When the compressor is off, the prediction error is low and residuals are similar to white noise. Due to its inaccuracies and the identified missing dynamics from Fig. 9, this model is not further validated. In the next subsections, the second group of charts (eg., Fig. 10) is omitted for brevity.

\section{B. Parameters of the $T_{i} T_{\text {evap }}$ model}

TABLE II. IDENTIFIED PARAMETERS: $T_{i} T_{\text {evap }}$ MODEL.

\begin{tabular}{|c||l||l|}
\hline PARAMETER & VALUE & STD. DEV. \\
\hline$R_{i a}$ & $9.0188 \cdot 10^{-1}$ & $3.5460 \cdot 10^{-2}$ \\
\hline$R_{e i}$ & $9.0348 \cdot 10^{-1}$ & $2.5121 \cdot 10^{-1}$ \\
\hline$C_{i}$ & $1.1600 \cdot 10^{4}$ & $1.6529 \cdot 10^{2}$ \\
\hline$C_{e}$ & $3.4342 \cdot 10^{2}$ & $9.9157 \cdot 10^{1}$ \\
\hline$T_{i}(0)$ & 14.774 & $1.0263 \cdot 10^{-2}$ \\
\hline$T_{\text {evap }}(0)$ & 16.181 & 3.6991 \\
\hline$A_{c}$ & 0.8383 & $2.6217 \cdot 10^{-2}$ \\
\hline $\exp \left(\sigma_{1}\right)$ & $-1.7406 \cdot 10^{1}$ & $5.6451 \cdot 10^{-2}$ \\
\hline $\exp \left(\sigma_{2}\right)$ & $-8.9551 \cdot 10^{-1}$ & $2.6646 \cdot 10^{-1}$ \\
\hline $\exp (e)$ & $-1.2246 \cdot 10^{1}$ & $1.1364 \cdot 10^{-1}$ \\
\hline Loglikelihood & 12096.4351 & \\
\hline
\end{tabular}

The residual analysis in Fig. 11 shows a clear improvement of model $T_{i} T_{\text {evap }}$ compared to $T_{i}$ and the cumulative periodogram is almost inside the confidence bands.

\section{Parameters of $T_{i} T_{\text {evap }} T_{e}$ model}

Model $T_{i} T_{\text {evap }} T_{e}$ outperforms in data fitting and the cumulative periodogram stays in the confidence bands. Figures 13 


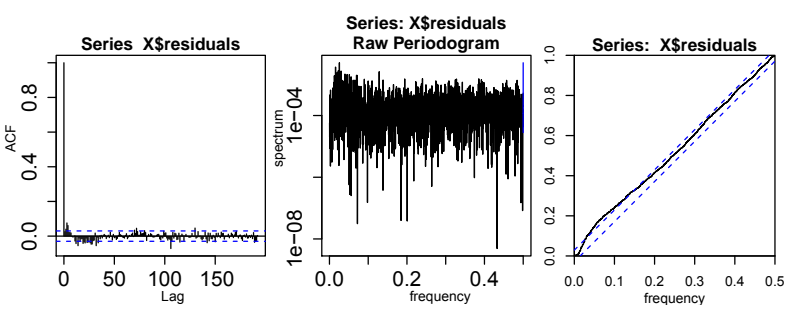

Fig. 11. Model residuals analysis: $T_{i} T_{\text {evap }}$.
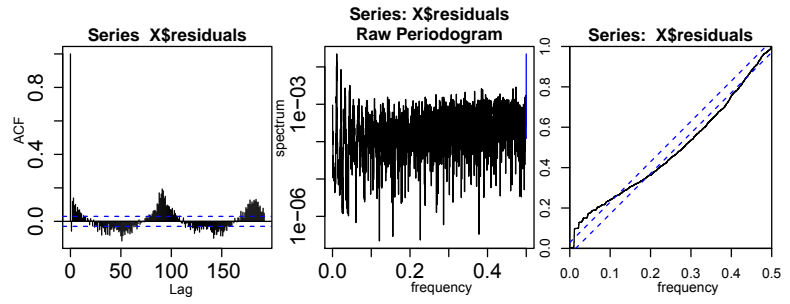

Fig. 12. Model residuals analysis: $T_{i} T_{\text {evap }}$ - validation data set.

TABLE III. IDENTIFIED PARAMETERS: $T_{i} T_{\text {evap }} T_{e}$ MODEL

\begin{tabular}{|c||l||l|}
\hline PARAMETER & VALUE & STD. DEV. \\
\hline$R_{e a}$ & $7.2869 \cdot 10^{-2}$ & $1.8571 \cdot 10^{-2}$ \\
\hline$R_{\text {evi }}$ & 2.2431 & $5.1971 \cdot 10^{-1}$ \\
\hline$R_{i e}$ & 3.7394 & 1.9380 \\
\hline$C_{i}$ & $4.4245 \cdot 10^{3}$ & $2.2810 \cdot 10^{3}$ \\
\hline$C_{e}$ & $1.0755 \cdot 10^{4}$ & $2.4514 \cdot 10^{3}$ \\
\hline$C_{\text {evap }}$ & $1.9177 \cdot 10^{1}$ & 4.8643 \\
\hline$T_{i}(0)$ & 14.774 & $8.6339 \cdot 10^{-3}$ \\
\hline$T_{e}(0)$ & 14.38 & 6.1042 \\
\hline$T_{\text {evap }}(0)$ & 18.568 & 5.5536 \\
\hline$A_{c}$ & $2.1808 \cdot 10^{-1}$ & $1.1258 \cdot 10^{-1}$ \\
\hline $\exp \left(\sigma_{1}\right)$ & $-1.7661 \cdot 10^{1}$ & $1.2498 \cdot 10^{1}$ \\
\hline $\exp \left(\sigma_{2}\right)$ & $-2.0051 \cdot 10^{1}$ & 2.4919 \\
\hline $\exp \left(\sigma_{3}\right)$ & $-6.2477 \cdot 10^{-1}$ & $1.0131 \cdot 10^{-1}$ \\
\hline $\exp (e)$ & $-1.1766 \cdot 10^{1}$ & $7.9326 \cdot 10^{-2}$ \\
\hline Loglikelihood & 12306.517 & \\
\hline & & \\
\hline \multicolumn{2}{|l}{} &
\end{tabular}
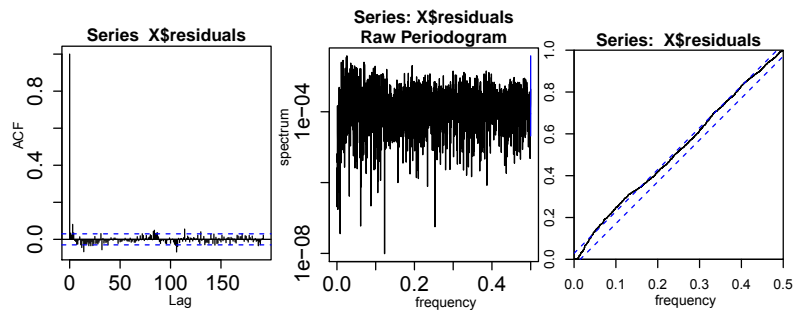

Fig. 13. Model residuals analysis: $T_{i} T_{\text {evap }} T_{e}$.

and 14 present the residuals analysis using respectively the identification data set and the validation data set. Hence it is concluded that this model seems capable of describing the observed dynamics of the refrigerator.

\section{Model selection}

Previous estimation trials have shown that model $T_{i} T_{\text {evap }} T_{e}$ leads to the highest likelihood value (12306) and best residuals properties. However, model $T_{i} T_{\text {evap }}$ has good residuals properties and a high likelihood value (12096). Moreover, identified parameters of model $T_{i} T_{\text {evap }}$ are closer to the prior estimates, compared to the parameters of $T_{i} T_{\text {evap }} T_{e}$ model, and using the validation data set it is found that $T_{i} T_{\text {evap }}$

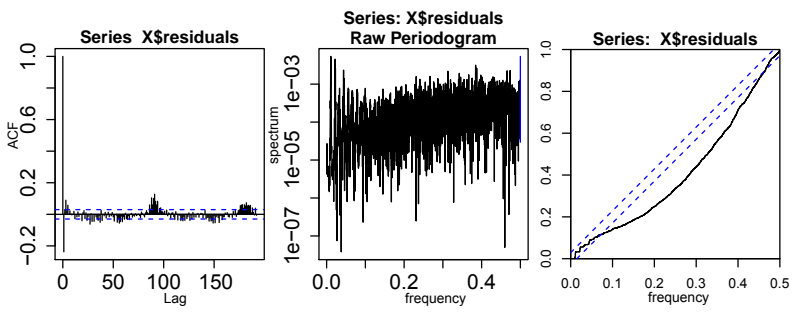

Fig. 14. Model residuals analysis: $T_{i} T_{\text {evap }} T_{e}$ - validation data set.

has the best performance. Therefore the choice of model $T_{i} T_{\text {evap }}$ as reference model for the given setup.

\section{CONCLUSION}

This study showed an application of grey-box stochastic modeling for household refrigeration systems. Identified models are simple, reliable and, since they are SDE-based, they can be used for forecasting, control and simulation. Thanks to the diffusion terms, model uncertainties are also provided. This study represents for the authors a starting point for the development of intelligent control of such systems as thermal storages for providing power balancing services to the utility in a Smart Grid context.

\section{ACKNOWLEDGMENT}

The authors acknowledge the financial support of iPower, a project within the Danish Strategic Platform for Innovation and Research within Intelligent Electricity (www.iPower.dk).

\section{REFERENCES}

[1] World Business Council for Sustainable Development (WBCSD), "Transforming the market: Energy efficiency in the buildings," 2009.

[2] B. Flynn, "Key smart grid applications," The Protection \& Control Journal (G.E), Dec. 2008

[3] G. Costanzo, A. Kosek, L. Ferrarini, G. Zhu, M. Anjos, and G. Savard, "An experimental study on load-peak shaving in smart homes by means of online admission control," in IEEE Innovative Smart Grid Technologies Europe (ISGT), Oct. 2012.

[4] C. J. Hermes and C. Melo, "Assessment of the energy performance of household refrigerators via dynamic simulation," Applied Thermal Engineering, vol. 29, no. 56, pp. 1153 - 1165, 2009.

[5] C. J. Hermes, C. Melo, F. T. Knabben, and J. M. Gonalves, "Prediction of the energy consumption of household refrigerators and freezers via steady-state simulation," Applied Energy, vol. 86, no. 78, pp. 1311 1319, 2009.

[6] J. Gupta, M. R. Gopal, and S. Chakraborty, "Modeling of a domestic frost-free refrigerator," International Journal of Refrigeration, vol. 30, no. 2, pp. $311-322,2007$.

[7] Danish Technical University - Department of Informatics and Mathematical Modeling, "Continuous time stochastic modeling," 2005.

[8] J. Møller, N. Carstensen, and H. Madsen, Stochastic State Space Modelling of Nonlinear systems - With application to Marine Ecosystems, ser. IMM-PHD-2010. Technical University of Denmark (DTU), 2011.

[9] H. Madsen, Time Series Analysis, ser. Texts in statistical science. Chapman \& Hall/CRC, 2008.

[10] N. R. Kristensen and H. Madsen, "Continuous time stochastic modelling, CTSM 2.3 - mathematics guide," DTU, Tech. Rep., 2003.

[11] H. Madsen and P. Thyregod, Introduction to General and Generalized Linear Models. CRC Press, 2010.

[12] N. R. Kristensen, H. Madsen, and S. B. Jørgensen, "Parameter estimation in stochastic grey-box models," Automatica, vol. 40, no. 2, pp. 225 $-237,2004$ 